\title{
Acute Renal Failure during Pregnancy
}

\author{
Dong-Su Jeon ${ }^{1}$, Tae-Hee Kim ${ }^{1 *}$, Hae-Hyeog Lee ${ }^{1}$, Dong Won Byun ${ }^{2}$ \\ ${ }^{1}$ Department of Obstetrics and Gynecology, Soonchunhyang University Bucheon Hospital, Bucheon, South Korea \\ ${ }^{2}$ Division of Endocrinology and Metabolism, Department of Internal Medicine, Soonchunhyang University Hospital, \\ Bucheon, South Korea \\ Email: *heeobgy@schmc.ac.kr
}

Received December 5, 2012; revised January 8, 2013; accepted February 6, 2013

\begin{abstract}
Acute renal failure during pregnancy is a very rare and dangerous medical complication. Here, we report a primigravida at 31 weeks gestation who complained of oliguria, high fever, flank pain, nausea, and vomiting for 3 days. The patient's history was unremarkable. Her laboratory findings and ultrasonography revealed acute renal failure. After delivery, the patient had no complications and normal laboratory findings. Thus, if the gestational age is appropriate to deliver the baby, prompt delivery is important to prevent acute renal failure during pregnancy.
\end{abstract}

Keywords: Acute Renal Failure; Pregnancy; Delivery; Pyelonephritis

\section{Introduction}

Acute renal failure during pregnancy presents an important clinical challenge. This disease is uncommon, occurring in only 1 of every 10,000 pregnancies [1]. In recent years, the incidence of acute renal failure has decreased in developed countries, but it continues to be associated with significant mortality and long-term morbidity [2]. Acute renal failure during pregnancy is associated with a high risk for maternal mortality (9\% - 55\%) [3]. General management of acute renal failure begins with correction of underlying etiological factors and removal of renal toxins [4]. Acute pyelonephritis can lead to acute renal failure in the pregnant women.

Here, we report a patient with acute renal failure during the third trimester of an otherwise uncomplicated pregnancy.

\section{Case Report}

A 29-year-old woman at 31 weeks gestation of her first pregnancy presented with a history oliguria, high fever, flank pain, nausea, and vomiting for 3 days. The patient's medical history was unremarkable. At the time of admission to our hospital, the patient appeared ill, her body temperature was $38.7^{\circ} \mathrm{C}$, and her pulse rate was 92 beats/min. Her blood pressure was 120/70 mmHg.

Laboratory tests revealed a white blood cell count of $9470 / \mu l$, a hemoglobin level of $10.8 \mathrm{~g} / \mathrm{dl}$, a platelet count

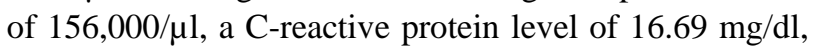
an erythrocyte sedimentation rate of $120 \mathrm{~mm} / \mathrm{hr}$, a blood

\footnotetext{
*Corresponding author.
}

urea nitrogen level of $34.3 \mathrm{mg} / \mathrm{dl}$, and a serum creatinine level of $5.1 \mathrm{mg} / \mathrm{ml}$. Serum protein, calcium, and electrolyte levels were normal, as were the results of liver function studies.

Her abdomen felt soft, but both flanks were tender. The uterus was appropriately enlarged for 31 weeks gestation. The fetal heartbeat was strong at approximately $140-160 / \mathrm{min}$. The results of the remaining general physical examinations were normal.

On the second hospital day, labor induction was performed because of renal symptoms. However, labor did not progress well, so the patient underwent an emergency Cesarean delivery of a live male newborn weighing 2090 g. The newborn had no other abnormalities.

We arranged a renal echo study on the first postoperative day, and it showed a bilateral swelling kidney with increased parenchymal echogenicity. The patient received 9 days of ceftriaxone $2.0 \mathrm{~g}$ treatment daily and conservative therapy with a good response. On the fourth postoperative day, the serum creatinine level was 0.8 $\mathrm{mg} / \mathrm{dl}$, and the patient was discharged. At follow-up, she remained well and renal function values continued to be within normal limits.

\section{Discussion}

Acute renal failure is an infrequent but life-threatening complication of pregnancy. Since the 1960s, the overall incidence of pregnancy-related acute renal failure has decreased from $1 / 3000$ to $1 / 15,000$ - 1/20,000. Similarly, the proportion of total cases of pregnancy-related acute renal failure has fallen from approximately $20 \%-40 \%$ in 
the 1960 s to approximately $2 \%-10 \%$ in the 1980 s [5-7]. Coincident with these declines, little change has been observed in the overall mortality and long-term morbidity rates [4].

Pregnancy has a minimal effect on renal function and is usually not associated with postpartum deterioration or development of end-stage renal disease. In general, no consensus has been established regarding a definition for renal failure during pregnancy, and definitions range from a creatinine level above $0.8 \mathrm{mg} / \mathrm{dl}$ to the requirement for dialysis [8].

The pathophysiology of renal failure in pregnancy can be categorized according to anatomical pathology, hemodynamic changes, abnormal substrate handling, and acidbase abnormalities. The most common cause of renal failure in pregnancy is preeclampsia; however, only about $1.5 \%$ - $2 \%$ of preeclampsia patients develop failure [8]. Renal failure is typically associated with septic abortion, preeclampsia, or uterine hemorrhage from placenta previa or placental abruption.

The initial management of renal failure in pregnancy commences with treatment of the underlying causes. Pyelonephritis can lead to sepsis and acute renal failure in both pregnant and non-pregnant patients; however, an increased risk of acute renal failure exists due to pyelonephritis in pregnancy independent of the presence or absence of sepsis [4]. One historical study showed that $25 \%$ of women with pyelonephritis in pregnancy demonstrated a significant decrement in glomerular filtration rate without sepsis [9]. The initial approach to management of our patient was similar to that for acute pyelonephritis management. She was administered antibiotics intravenously.

Our case was considered acute renal failure associated with pyelonephritis. In conclusion, acute renal failure during pregnancy is a rare condition and remains a serious medical complication of pregnancy. The treatment of acute renal failure during pregnancy is correction of underlying disease. Therefore, it is important to quickly find the cause of acute renal failure. We experienced one case of acute renal failure during pregnancy and reported this case with a brief review of relevant literature.

\section{REFERENCES}

[1] P. H. Chung, J. S. Abramowicz, D. M. Edgar and D. M. Sherer, "Acute Maternal Obstructive Renal Failure in a Twin Gestation Despite Normal Physiological PregnancyInduced Urinary Tract Dilation," American Journal of Perinatology, Vol. 11, No. 3, 1994, pp. 242-244. doi:10.1055/s-2008-1040755

[2] N. Pertuiset and J. P. Grunfeld, “Acute Renal Failure in Pregnancy,” Baillière's Clinical Obstetrics and Gynaecology, Vol. 8, No. 2, 1994, pp. 333-351. doi:10.1016/S0950-3552(05)80324-4

[3] K. R. Goplani, P. R. Shah, D. N. Gera, M. Gumber, M. Dabhi, A. Feroz, et al., "Pregnancy-Related Acute Renal Failure: A Single-Center Experience,” Indian Journal of Nephrology, Vol. 18, No. 1, 2008, pp. 17-21. doi:10.4103/0971-4065.41283

[4] H. S. Gammill and A. Jeyabalan, "Acute Renal Failure in Pregnancy,” Critical Care Medicine, Vol. 33, No. 10, 2005, pp. S372-S384. doi:10.1097/01.CCM.0000183155.46886.C6

[5] J. P. Grunfeld and N. Pertuiset, "Acute Renal Failure in Pregnancy: 1987,” American Journal of Kidney Diseases, Vol. 9, No. 4, 1987, pp. 359-362.

[6] P. Stratta, C. Canavese, M. Dogliani, T. Todros, L. Gagliardi and A. Vercellone, "Pregnancy-Related Acute Renal Failure,” Clinical Nephrology, Vol. 32, No. 1, 1989, pp. 14-20.

[7] J. H. Turney, C. M. Ellis and F. M. Parsons, "Obstetric Acute Renal Failure 1956-1987,” BJOG: An International Journal of Obstetrics \& Gynaecology, Vol. 96, No. 6, 1989, pp. 679-687. doi:10.1111/j.1471-0528.1989.tb03282.x

[8] C. M. Nzerue, K. Hewan-Lowe and C. Nwawka, “Acute Renal Failure in Pregnancy: A Review of Clinical Outcomes at an Inner-City Hospital from 1986-1996," Journal of the National Medical Association, Vol. 90, No. 8, 1998, pp. 486-490.

[9] P. J. Whalley, F. G. Cunningham and F. G. Martin, "Transient Renal Dysfunction Associated with Acute Pyelonephritis of Pregnancy,” Obstetrics \& Gynecology, Vol. 46, No. 2, 1975, pp. 174-177. 